\title{
O CURSO DE PEDAGOGIA EM INSTITUIÇÕES DE ENSINO SUPERIOR DE TERESINA - PIAUÍ, BRASIL: INCLUINDO OU EXCLUINDO OS HOMENS?
}

\author{
EL CURSO DE PEDAGOGÍA EM INSTITUCIONES DE ENSEÑANZA \\ SUPERIOR DE TERESINA - PIAUÍ, BRASIL: INCLUYENDO O EXCLUYENDO A \\ LOS HOMBRES?
}

PEDAGOGY COURSES IN HIGHER EDUCATION INSTITUTION AT
TERESINA - PIAUI, BRAZIL: INCLUDING OR EXCLUDING MEN?

Jânio Jorge Vieira de ABREU ${ }^{1}$

RESUMO: O presente estudo analisa o ingresso de homens e mulheres nos Cursos de Pedagogia de instituições de Ensino Superior de Teresina (PI) - Brasil, buscando compreender como as masculinidades e as feminilidades são construídas na cultura escolar desses cursos. Fez-se um diálogo interdisciplinar com os/as pesquisadores/as: Oliveira (2004); Burke (2004); Connell (1995); Júlia (2001); Lopes (1999); Louro (1997) e outros. Realizou-se uma pesquisa documental e de campo em seis instituições por meio de questionários e entrevistas com 94 sujeitos e análise de documentos institucionais. Chegouse às seguintes conclusões: os currículos dos cursos de Pedagogia estudados têm sido ampliados, mas a comunidade acadêmica e escolar restringem-nos à formação para a Educação Infantil e por esse motivo rejeita os homens para esse nível de ensino; o magistério reflete uma cultura acadêmica e escolar subsistente que, a despeito dos anseios profissionais masculinos e femininos, foi historicamente marcado pela divisão sexual do trabalho em determinados espaços escolares. Em algumas experiências, o magistério é dimensionado por concepções que educam, transformam, mas também excluem, reproduzem preconceitos e estereótipos, consequências de fatores econômicos, sociais e culturais que ora estimulam os homens e mulheres à inserção, ora forçam-nos à evasão do referido campo de trabalho. Os homens e mulheres, no cotidiano acadêmico dos cursos pesquisados, não obstante os estereótipos e preconceitos sofridos e até a intolerância da comunidade ao curso que realizam, criam identidades, revelam sentimentos, adquirem habilidades, produzem conhecimentos e, mais que constroem ou reconstroem masculinidades e feminilidades, reinventam homens e mulheres professores/as.

PALAVRAS-CHAVE: Masculinidades. Pedagogia. Educação infantil. Exclusão.

RESUMEN: El presente estudio analiza el ingreso de hombres y mujeres en los Cursos de Pedagogía de instituciones de Enseñanza Superior de Teresina (PI), Brasil, buscando

\footnotetext{
1 Universidade Estadual do Piauí (UESPI), Teresina- PI - Brasil. Docente. Coordenação do Curso de Licenciatura em Pedagogia do Campus Clóvis Moura - Cidade de Teresina (PI), Brasil. Pedagogo, Mestre em Educação e Doutor em Educação pela Universidade Federal do Piauí (UFPI). Exerce o Cargo de Professor Adjunto em Regime de Dedicação Exclusiva na Uespi atuando nas seguintes áreas: pesquisa educacional, fundamentos históricos e antropológicos da educação; gênero, educação e diversidade cultural e outras. ORCID: <https://orcid.org/0000-0001-6757-0321>. E-mail: profjanioabreu@gmail.com
}

RIAEE - Revista Ibero-Americana de Estudos em Educação, Araraquara, v. 13. n. esp. 2, p. 1518-1534, set., 2018. ISSN: $1982-5587$. 
compreender cómo las masculinidades y femenidades son construídas en la cultura escolar de esos cursos. Se hizo un diálogo interdisciplinar con los/las pesquisadores/ras: Oliveira (2004); Burke (2004); Connell (1995); Júlia (2001); Lopes (1999); Louro (1997) y otros. Se llevó a cabo una pesquisa documental y de campo en seis instituciones a través de cuestionarios y entrevistas con 94 sujetos y análisis de documentos institucionales. Se llegó a las siguientes conclusiones: los currículos de los cursos de Pedagogía estudiados han sido ampliados, pero la comunidad académica y escolar los restringen a la formación para Educación Infantil y por ese motivo rechaza a los hombres para ese nivel de enseñanza; el magisterio, refleja una cultura académica y escolar subsistente que, a pesar de los anhelos profesionaless masculinos y femeninos, fue históricamente marcado por la división sexual del trabajoo en determinados espacios escolares. En algunas experiencias, el magisterio es dimensionado por concepciones que educan, transforman, pero también excluyen, reproducen prejuicios y estereotipos, consecuencias de fatcores económicos, sociales y culturales que em ciertos momentos estimulan a los hombres y mujeres a la inserción y en otros, los fuerzan a la evasión del referido campo de trabajo. Los hombres y mujeres en el cotidiano académico de los cursos investigados, a pesar de los esteriotipos y prejuicios sufridos e incluso de la intolerancia de la comunidad al curso que realizan, crean identidades, revelan sentimientos, adquieren habilidades, producen conocimientos $y$, más que construyen o reconstruyen masculinidades y femenidades, reinventan hombres y mujeres profesores/as.

PALABRAS CLAVE: Masculinidades. Pedagogía. Educación infantil. Exclusión

ABSTRACT: This study analyze the entry of men and women in the Pedagogy courses of higher education institution at Teresina (PI) - Brazil, attempting to understand how the masculinities and femininities are built in these courses scholar cultures. An interdisciplinary dialogue was made with the following researchers: Oliveira (2004); Burke (2004); Connell (1995); Júlia (2001); Lopes (1999); Louro (1997) and others. A field and documentary research was carried out in six institutions through questionnaires and interviews with 94 individuals and institutional documents analysis. The study arrived at the following conclusions: The curriculum of the pedagogy courses studies have been expanded, but academic and scholar communities limit them to childhood education. For this reason, reject men for this teaching level; magisterium reflects remaining academic and scholar culture is historically marked by work sexual division in some scholar spaces, despite male and female professional expectations. In some experiences, magisterium is dimensioned by concepts, which educate, transform but also exclude and reproduce prejudices and stereotypes, consequences of economic, social and cultural factors that can stimulate men and women inclusion or force to dropout this working field. Men and women, in academic routine of researched courses, notwithstanding stereotypes and prejudices suffered and even community intolerance to the course, create identities, reveal feelings, develop abilities, produce knowledge ad build and rebuild masculinities and femininities, recreating male and female professors.

KEYWORDS: Masculinities. Pedagogy. Childhood education. Exclusion.

\section{Introdução}


As pesquisas que contemplam o campo da Educação e Relações de Gênero, especificamente as masculinidades e as feminilidades discentes abordadas neste trabalho, exigem uma investigação e uma discussão interdisciplinar, pois gênero, masculinidades e feminilidades são aqui concebidos como construções sociais e históricas, produzidas por uma cultura de valores, simbologias ${ }^{2}$ que, em muitas situações, subsistem às ações intencionais humanas e às relações de poder, contemplando assim diversos campos de conhecimento na compreensão das referidas categorias.

Diante do exposto, na escolha das fontes e na abordagem epistemológica, trabalhou-se na perspectiva da História Cultural em interdisciplinaridade com outras perspectivas, pois ela se posiciona em favor da ampliação do campo de visão do pesquisador, da variedade das abordagens da ciência e da inovação teórica e metodológica. Isso significa que a História Cultural oferece diferentes possibilidades de estudo abrangendo os sujeitos e as agências que produzem a cultura, neste estudo, especialmente, a cultura escolar, e também os meios pelos quais ela é realizada, transmitida, trazendo para a área de pesquisa uma ampliação de fontes e objetos de investigação e dando aos pesquisadores/as maior liberdade de ação (BURKE, 2004).

Nesse sentido, a inclusão de homens e mulheres no Curso de Licenciatura em Pedagogia só pode ser compreendida mediante um olhar sobre a cultura escolar e acadêmica, especialmente sobre as masculinidades e as feminilidades nos caminhos do magistério e a problemática em torno da formação dessas categorias, entre outros aspectos. Incluem-se nesse percurso a opção pelo curso, a aceitação na academia, no estágio, enfim, a participação masculina e feminina nos espaços formativos e, consequentemente, no campo de trabalho.

Com esse propósito, procedeu-se a uma pesquisa documental e de campo nos Cursos de Licenciatura em Pedagogia das instituições públicas e privadas de Teresina - PI, Brasil. Foi solicitada autorização para pesquisa em nove instituições, incluindo dois Núcleos de Educação Aberta a Distância. Destas selecionaram-se seis instituições, incluindo um Centro de Educação Aberta a Distância, que oferece o Curso de Licenciatura em Pedagogia. O trabalho foi iniciado pela análise das matrizes curriculares dos cursos. Em seguida, procedeu-se à construção do perfil discente dos/as alunos/as do Curso de

${ }^{2}$ Simbologia expressa um conjunto de símbolos pelos quais um grupo ou sociedade transmite valores. Símbolo é definido pelo antropólogo White (1968, p. 182) como "alguma coisa cujo valor ou significado é atribuído pelas pessoas que o usam". A expressão coisa é usada no sentido de explicitar que um símbolo pode ter a forma de um objeto material, uma cor, um som, um cheiro, o movimento de um objeto, um gosto etc. 
Licenciatura em Pedagogia contemplando dados de identificação, aspectos da vida pessoal, familiar, escolar, acadêmica e social.

Prossegue-se o texto discutindo os conceitos ou concepções e práticas de gênero, masculinidades, feminilidades, cultura acadêmica e escolar nos cursos de pedagogia no sentido de compreender como são construídas tais categorias teóricas e empíricas na academia científica.

\section{Educação, gênero e masculinidades: aspectos históricos e conceituais}

Discutir as masculinidades discentes na cultura escolar exige compreender gênero e a apropriação que se faz dessa categoria em campos de conhecimentos diversos, especialmente aqueles que possibilitam mais a interdisciplinaridade com o campo da educação, no sentido de responder inquietações como essas aqui apresentadas e contribuir para promover mudanças significativas em favor dos direitos humanos.

"Gênero" tem significação polissêmica, podendo ser utilizado para atribuições diversas em diferentes campos do conhecimento, o que permite interpretá-lo como conceito e categoria de análise. Para as Ciências Humanas e Sociais, refere-se à elaboração cultural das noções de masculinidade e feminilidade aquilo que se diz a partir das diferenças estabelecidas entre homens e mulheres, quaisquer que sejam as suas posições e orientações - heterossexuais, homossexuais, transexuais, travestis, transgêneros e outras.

Gênero, numa compreensão abrangente, constitui os predicados ou características que um ser, de qualquer origem, tem em comum com outro e que lhe determinam a essência, acrescida da diferença. Isso é válido tanto para agrupamento de indivíduos, ideias, maneiras, estilos, quanto para definir espécie, tipo, objetos, fatos que tenham características comuns (FERREIRA, 2009).

Assim, para as diversas interpretações de gênero convergem significados, pois gênero é espécie e várias espécies constituem um gênero, mas pode-se afirmar, também, que nesse campo nada pode ser definido precisamente, mas, apenas, por aproximação. Isso ocorre desde a comparação feita nas relações entre indivíduos muito semelhantes entre si e aos ancestrais e que se entrecruzam até na constituição de uma unidade biológica fundamental.

Para discorrer sobre a categoria gênero ou masculinidades discentes, como uma construção social e histórica, ou seja, do que se diz sobre homens ou sobre mulheres em 
determinados espaços ou atividades, significa identificá-la no contexto e na temática específica na qual se insere e à qual se relaciona num determinado período histórico. Para facilitar essa compreensão, apresenta-se inicialmente uma definição específica, que parte da biologia e atinge uma dimensão social, qual seja: gênero é uma construção social que se faz a partir de determinadas características do corpo, o que influencia no modo de viver das pessoas de uma sociedade em determinado período de suas vidas e a partir da cultura social nesta apropriada. Trata-se de uma representação valorativa, simbólica, consequência de um modelo de sociedade.

Para Louro (1997), é por meio das feministas anglo-saxãs que gênero passa a ser usado como distinto de sexo, rejeitando o determinismo biológico, até então implícito no uso de termos como sexo ou diferença sexual. Elas desejavam acentuar, por meio da linguagem, o caráter fundamentalmente social das distinções baseadas no sexo. Para Monteiro (2013, p. 335), no período entre as décadas de 1960 e 1990, acontecem mudanças importantes nas representações e práticas de gênero no Brasil e no mundo, as quais desencadearam:

[...] a maior inserção das mulheres na esfera pública e o início do debate nacional sobre masculinidades e feminilidades dissonantes: homossexuais, bissexuais, transexuais etc. Acontece também uma pluralização da experiência da masculinidade como resultado desses processos, incluindo aí toda a gama de masculinidades recentes, como "metrossexuais", o "novo homem", e outros rótulos que ganharam destaque ao longo de anos recentes. [...]. A ideia de um "novo homem" não é exatamente nova: debates sobre mudanças nas relações entre os gêneros emergem de tempos em tempos, e nesses períodos debate-se a mudança de comportamento dos homens.

O autor supracitado afirma haver grande especulação em função das causas dessa discussão, mas atribui isso, especialmente, à segunda onda do feminismo iniciada nos anos 1960, pois é nesse momento que grandes mudanças sociais, culturais, econômicas, demográficas e políticas acontecem no Brasil, e as novas masculinidades começam a se delinear de forma mais clara (MONTEIRO, 2013). Partindo desse pressuposto, não há um tipo único de mulher nem um tipo único de homem que emerge desta ou daquela forma de sociabilidade, ou seja, cada vez mais vê-se a possibilidade de se ter agentes masculinos e femininos de tipos variados.

Nessa abordagem, o conceito de gênero "serve, assim, como uma ferramenta analítica que é ao mesmo tempo política". Vale ressaltar que dirigir o foco para o caráter fundamentalmente social não é pretensão de negar a biologia, mas destacar a construção

RIAEE - Revista Ibero-Americana de Estudos em Educação, Araraquara, v. 13. n. esp. 2, p. 1518-1534, set., 2018. ISSN: $1982-5587$. 
social e histórica produzida sobre as características biológicas (MONTEIRO, 2013, p. 21). É o que também afirma Connel (1995, p. 189): “no gênero, a prática social se dirige aos corpos". O conceito refere-se ao modo como as características sexuais são compreendidas e representadas ou como são trazidas para a prática social e tornadas partes do processo histórico.

Connell (1995, p. 189), ao tratar da construção e reconstrução da masculinidade, sustenta:

Existe uma narrativa convencional sobre como as masculinidades são construídas. Nessa narrativa toda cultura tem uma definição da conduta e dos sentimentos apropriados para os homens. Os rapazes são pressionados a agir e a sentir dessa forma e a se distanciar do comportamento das mulheres [...] a feminilidade é compreendida como o oposto. A pressão em favor da conformidade vem das famílias, das escolas, dos grupos de colegas, da mídia e finalmente, dos empregadores. A maior parte dos rapazes internaliza essa norma social e adota maneiras e interesses masculinos, tendo como custo, frequentemente, a repressão dos sentimentos $[\ldots]$.

Continuando a mesma discussão, o autor supramencionado oferece uma breve definição de masculinidade: “é uma configuração de prática em torno da posição dos homens na estrutura das relações de gênero" (CONNELL, 1995, p. 189). Esclarece mais: "Existe normalmente mais de uma configuração desse tipo em qualquer ordem de gênero de uma sociedade" (CONNELL, 1995, p. 189). Um homem que se constitui em vários homens, vários masculinos numa única história de vida. É a imagem de uma realidade social inscrita e refletida em corpos humanos. Clodovil, um estudante de pedagogia com orientação homossexual, em seu discurso, reflete a definição do autor supracitado:

$O$ masculino ele é muito relativo. $O$ masculino pode ter trejeitos femininos, pode ter trejeitos masculinos. Eu acho que o trejeito, o trejeito não, a característica que você fala, né, deve ser comum entre o público, eu acho que deve ser a tolerância com as outras diferenças. Por que, assim, do que valeria se fôssemos todos homogêneos, sem as suas diferenças, tem que ter a heterogeneidade (CLODOVIL, VI BLOCO PEDAGOGIA, F-C).

[...] A gente viu que, é... a distância entre homem e mulher ela era gigantesca, ela diminuiu um pouco, ela ainda continua, mas ela diminuiu! E, hoje, uma mulher é... ela consegue ser mais masculina, não no sentido de é... ser, de ter características masculinas, mas de fazer trabalhos é... masculinos, de fazer atividades masculinas e ao mesmo tempo que existia essa mediação de uma mulher fazer trabalhos é... atividades proporcionadas que eram do homem, existe também é... a... Existia também a oportunidade de o homem mesmo com a sua 
masculinidade fazer atividades que eram voltadas, relacionadas... femininas. (NERO, VI BLOCO PEDAGOGIA, U-A).

É nessa perspectiva que Nero concebe o que é ser masculino. Para Oliveira (2004), as posições do homem e da mulher na sociedade contemporânea tendem a ser cada vez mais aproximadas entre si. Isso porque se o sexo biológico já foi cultural e socialmente determinante para a divisão sexual do trabalho, na atualidade as atividades laborais cada vez menos requerem especificidades vinculadas ao sexo biológico, há uma crescente inserção de homens e mulheres em atividades antes destinadas apenas ao outro sexo.

Embora alguns homens tenham apresentado uma concepção masculina pautada nos estereótipos de sexo e de gênero, nenhum deles atribui a presença ou a redução desta às dificuldades de estudo ou de desenvolvimento de atividades acadêmicas no Curso de Licenciatura em Pedagogia, mas sim à restrição das escolas, de alguns professores/as, dirigentes na comunidade acadêmica ou da cultura escolar.

Ser masculino vem na minha mente virilidade, é... força, competência também, responsabilidade, ser uma pessoa humana, de bem, de bom caráter, capaz de formar mentes. Feminino, da mesma forma... tirando a virilidade que é essa aí é uma característica mesmo masculina, mas da mesma forma, uma capacidade também de formar opiniões é desde a infância... até, até hoje (VANDERLEI, IV BLOCO PEDAGOGIA, F-A).

Esta e outras concepções são apresentadas por muitos homens. Segundo os estudos de Nolasco (1993), os homens, particularmente, são instigados desde cedo a falar e a valorizar o sexo não como possibilidade de expressão de si mesmos, mas como maneira de reproduzir o modelo de comportamento para eles determinado.

Os/as entrevistados/as neste trabalho, ao se posicionarem acerca das masculinidades e feminilidades ou do ser homem e do ser mulher na sociedade brasileira, até apresentam concepções abertas com relação à inserção do homem e da mulher no mercado de trabalho, o que é uma das formas de perceber os avanços que temos na construção da equidade de gênero. No entanto, muitos homens e mulheres confundem masculinidades com orientação sexual e ainda são muito marcados por preconceitos de sexo e de gênero, por isso, em algumas passagens dos seus depoimentos são contraditórios; na realidade, apresentam concepções ainda fortemente construídas com base nas diferenças sexuais. São construções, elaborações resultantes das representações e práticas muito presentes na cultura humana e que refletem na cultura acadêmica e escolar, o que será discutido de forma mais aprofundada no texto que segue.

RIAEE - Revista Ibero-Americana de Estudos em Educação, Araraquara, v. 13. n. esp. 2, p. 1518-1534, set., 2018. ISSN: $1982-5587$. 


\section{Masculinidades e feminilidades na cultura acadêmica e cultura escolar dos cursos de Licenciatura em Pedagogia}

O resultado do trabalho desenvolvido pela escola básica e pela universidade - a educação produz cultura, gera posicionamentos sociais e políticos, possibilita e conduz as pessoas a agir em suas comunidades conscientes de suas condições de vida e do papel social que exercem. Assim, pensar e atuar sob a ótica educativa é fazê-lo na perspectiva de uma produção cultural que valorize e se aproxime da vida existente em determinadas localidades, em suas especificidades, diversidades e complexidades, no sentido de estar em consonância com a realidade, mas trabalhando as contradições existentes ou superar as práticas reprodutoras das desigualdades de oportunidades em prol dos direitos humanos.

Nesse sentido, o conceito de cultura escolar e cultura acadêmica são utilizados para colocar em evidência a função da escola básica e da universidade como produtoras de conhecimentos e transmissoras de uma cultura específica no quadro do processo de socialização e integração dos/as estudantes e professores/as (BARROSO, 1995). No presente texto, procura-se ampliar esse sentido relacionando a cultura acadêmica com a cultura escolar como culturas interligadas pela formação na universidade para atuação na escola básica.

Cultura escolar é abordada neste trabalho como "aquele conjunto de saberes que, uma vez organizados, didatizados, compõem a base de conhecimentos sobre a qual trabalham professores e alunos”. Em Júlia (2001), cultura escolar é discutida sob uma abordagem histórica, como uma mescla de normas e práticas, que definem conhecimentos a ensinar e condutas a inculcar que, em conjunto, “[...] permite a transmissão desses conhecimentos e a incorporação de comportamentos" (JÚLIA, 2001, p. 2).

Para distinguir cultura escolar de cultura acadêmica ou universitária, apresenta-se esta última como "um conjunto de normas e práticas que professores/as e estudantes concretizam na universidade, e, portanto, como uma maneira de expressar normas e práticas científicas de estudantes, pesquisadores/as, autores/as e professores/as universitários" (DUARTE, 2008, p. 653). Na concepção do mesmo autor, cultura escolar é definida como um conjunto de normas e práticas estabelecidas por professores/as e alunos/as no ensino básico, lugar em que as práticas científicas são apropriadas, reelaboradas, reutilizadas e reorientadas (DUARTE, 2008).

Nesse sentido, procura-se mostrar, para além do conjunto de normas criadas e estabelecidas na universidade e na escola básica, a apropriação particular que os agentes 
escolares e acadêmicos e toda a comunidade envolvida nos dois contextos fazem delas, quando pensam o ensino, a aprendizagem, o ideal de professor/a, o ideal de aluno/a, o currículo, o homem, a mulher, etc., nas suas concepções e práticas cotidianas. Considerando tais aspectos, apresentam-se, inicialmente, relatos de docentes os quais refletem a cultura escolar subsistente no ensino básico e superior.

Pode parecer preconceito mas eu acho que não é, mas assim, os homens têm uma facilidade de maior concentração, de... se a gente passa uma atividade, eles são mais... é... como eu posso dizer? Eles cumprem mais rigidamente essa obrigação, as meninas tendem a se dispersar mais [...]. Eu sei que as mulheres costumam dizer que nós homens não conseguimos fazer duas coisas ao mesmo tempo né... brincadeiras à parte, mas eu acho que tem essa coisa da gente se concentrar/focar mais do que as meninas (MARX, PROFESSOR PEDAGOGIA, $U-B$ ).

As diferenças entre alunos e alunas nos depoimentos de alguns professores tendem a ser naturalizadas a partir do sexo biológico. A fala dos homens revela a existência de preconceitos sexuais no tocante às mulheres. Há na concepção de alguns a desvalorização das atividades acadêmicas das alunas em relação às atividades acadêmicas dos alunos. A divisão sexual quando não é operada nos corpos é realizada nas mentes dos professores. Os professores com essa postura separam mulheres de homens muito mais nos valores, nos conceitos de habilidade e capacidade do que nos espaços físicos e de papéis ou funções escolares. Há professoras/as que apresentam concepções opostas desconsiderando e invertendo as posições ou construindo outros estereótipos.

A única coisa que eu percebo é que alguns homens têm dificuldade, não são todos, muitos até se superam. Essa questão de arte, essa questão da criação, por exemplo, na disciplina de arte e educação...nessa parte mais pedagógica de confecção, de recursos, de materiais. Mas eles se superam em outras atividades (CRISÁLIDA, PROFESSORA COORDENADORA PEDAGOGIA, F-C).

Quando eu fazia o científico, eu tive um professor de Física, e como eu já falei inicialmente [...] eu sempre terminava primeiro as atividades. E quando eu terminava que eu mostrava, ele me detonava né. Então ele dizia assim, olhava pro papel, olhava pra minha cara como quem dizia "Não tô acreditando no que eu tô vendo", e olhava pra turma toda e recriminava os meninos né. Eu lembro de numa prova de Física, que ele fez uma questão de pegadinha [...] E só eu acertei na sala, todo mundo errou, e aí ele ficou pê da vida porque que eu acertei, porque que eu tinha esse raciocínio né de acertar essa questão? Então, ele tinha dificuldade de me dá um 10 porque para ele 10 em Física para mulher era um absurdo (PROFESSORA SALETE, PEDAGOGIA, F-A). 
Ambos os espaços são palcos de representações e práticas masculinizantes e feminilizantes que, embora possam ser caracterizados como estereótipos, são resultados de concepções curriculares passadas ou presentes, mas que são consequências de um ideal de professor/a originado nos primórdios do Sistema Escolar. No entanto, vale destacar que os/as mesmos/as autoras/as e executoras/as dessas ações são capazes de superar tais concepções no sentido de produzir culturas diferentes que desfaçam o gênero incluindo e respeitando as diversidades.

Ensina-se como deve ser um homem professor? Restringem-se gestos, destacam-se habilidades, limitações, etc. Características ideais? Seria esse modelo, essa concepção de professor(a), que vem ao longo da história da educação desestimulando os homens a ingressar no magistério? Na escola contemporânea, Carvalho (1999, p. 120-121) constatou:

[...] a existência de uma prática pedagógica própria do primário, construída sobre pressupostos que subsidiam também as práticas de maternidade, uma matriz cultural comum tanto aos ideais de boa professora, quanto de boa mãe e que remete a uma concepção de infância, um conceito de cuidado infantil e a normas sobre adequação das mulheres a essas tarefas, todas elas ideias social e historicamente construídas. Este modelo ideal de professor/a era produzido, transmitido e reproduzido também no interior da própria escola e fazia parte da cultura escolar partilhada pelos que ali trabalhavam.

Para Pincinato (2007), as diferenças entre os sexos são transferidas para as profissões, o que confere à docência significados femininos pela associação direta à maternidade e ao ato de cuidar das crianças. A restrição aos homens vem em função disso, mas vale ressaltar que o processo de feminização do magistério, incluindo aí os cursos de Pedagogia, também está relacionado a fatores econômicos, sociais, culturais, às relações de poder, ou seja, à forma como, em muitas situações, se estabelecem as relações de gênero na sociedade (LOPES, 1999; SOARES, 2004; ABREU, 2003). Mesmo havendo, historicamente, a intencionalidade, uma finalidade social e política que, contribuindo para o processo de feminização do magistério, atualmente os currículos dos cursos de Pedagogia, respeitadas as lacunas existentes, preparam profissionais para trabalharem na Educação Infantil, anos iniciais do Ensino Fundamental, em outras atividades pedagógicas. Sendo os homens também responsáveis pelo cuidado de crianças, podem obter a formação e atuar no referido campo de trabalho. No entanto, como mostra o depoimento a seguir, a comunidade escolar teresinense ainda oferece resistência aos homens na Educação Infantil. 
Então eu acho que há uma certa estranheza ou rejeição aos homens na Educação Infantil em si, seja por conta disso, porque tem-se a visão de que a mãe cuida mais, de que a mãe ama, de que a mãe vai dar um auxílio maior do que o pai, que logicamente é a figura do homem né. [...]. Porque na Educação Infantil em si, a gente às vezes tem que levar a criança no banheiro, a gente às vezes tem que limpar esta criança, então um pai ou uma mãe logicamente eles não vão querer sua criança tendo contato com um homem, principalmente se esta criança for do sexo feminino. Então é um pouco complicado por isso. [...] (JANDIRA, IV BLOCO PEDAGOGIA, $U-A)$.

Desde o surgimento da escola e da composição do sistema escolar brasileiro, existem um modelo e um ideal de professor e de professora que estão presentes não só na escola, mas são reflexos e refletem na sociedade. São concepções acadêmica e socialmente construídas e que permanentemente são reconstruídas como parte da cultura escolar, orientando desde a vocação ou a inserção, passando pelo processo de formação do/a professor/a nos cursos de magistério ou faculdades de Educação, até a prática docente nas escolas. Ensina-se como deve ser um bom professor: qualidades, defeitos, etc. É esse modelo, essa concepção de professor(a), que vem, ao longo da história da educação, transformando a educação escolar em guetos sexuais. São valores de uma cultura escolar histórica e social, portanto não é neutra, é intencional.

Uma política, um programa, um projeto educacional, uma prática ou um processo de ensino e aprendizagem, por mais organizado ou planejado que seja, materializado em ações das mais simples às mais burocráticas ou sofisticadas, se não contribuir para a compreensão da realidade ou para a conscientização dos alunos e alunas no sentido de que eles possam conquistar ou fazer valer seus direitos, obtendo uma vida próspera e cidadã, não terá reconhecimento nem relevância social. O exercício de educar não é tarefa somente da escola (como mencionado anteriormente) e, embora o espaço escolar possa ser um local privilegiado, ele não é o único nem sempre o melhor local e o mais eficiente ou eficaz no desenvolvimento de práticas educativas. Como mostram algumas dirigentes entrevistadas neste trabalho, o currículo, as diretrizes, a legislação, não têm conseguido assegurar uma base para a construção da identidade do pedagogo, o que vem causando muita inquietação no meio acadêmico:

Eu acho que o curso deveria ter... inclusive, novas diretrizes que foram aprovadas agora, a Pedagogia hoje tem que ser reformulada. Como te falei anteriormente, e nós temos até o próximo ano para redefinir essas diretrizes. Eu acho que, particularmente nós formamos professor para dar aula no ensino infantil e até o quinto ano do ensino fundamental, isso não quer dizer que ele não vá para outros espaços educacionais. Mas ir

RIAEE - Revista Ibero-Americana de Estudos em Educação, Araraquara, v. 13. n. esp. 2, p. 1518-1534, set., 2018. ISSN: $1982-5587$. 
para outros espaços educacionais é uma exceção. $70 \%$ vai para sala de aula (OLGA, PROFESSORA COORDENADORA PEDAGOGIA, U-A).

A Pedagogia é um campo de conhecimentos sobre a problemática educativa na sua totalidade e historicidade e, ao mesmo tempo, uma diretriz orientadora da ação educativa. Essa dimensão da constituição do campo de conhecimento da Pedagogia possibilitou e possibilita grande abrangência no campo de atuação do pedagogo, uma excessiva variação na composição de currículos do curso em todo o Brasil, contribuindo para um sério problema de identidade.

Qualquer concepção ou conceito de Pedagogia deve estar em consonância com o conceito de educação do sistema escolar e da sociedade na qual está inserida, definições essas que podem explicitar e justificar o campo de atuação do pedagogo e uma composição curricular para o referido curso, uma vez que a educação constitui o objeto de estudo da Pedagogia.

Com base em tal afirmação, a Pedagogia é concebida como um: “[...] campo do conhecimento que se ocupa do estudo sistemático da educação, isto é, do ato educativo, da prática educativa concreta que se realiza na sociedade como um dos ingredientes básicos da configuração da atividade humana", sendo a "[...] educação o conjunto das ações, processos, influências, estruturas, que intervêm no desenvolvimento humano de indivíduos e grupos na sua relação ativa com o meio natural e social, num determinado contexto de relações entre grupos e classes sociais" (LIBÂNEO, 2005, p. 30) ou, mais especificamente:

[...] uma prática social que atua na configuração da existência humana individual e grupal, para realizar nos sujeitos humanos as características de "ser humano", numa sociedade em que as relações sociais baseiam-se em relações de antagonismo, em relações de exploração de uns sobre outros, a educação só pode ter cunho emancipatório, pois a humanização plena implica a transformação dessas relações (LIBÂNEO, 2005, p. 30).

Seria, assim, necessário, dado o objeto de estudo da Pedagogia, estabelecer um estatuto científico desta, pois, como é consenso entre muitos pesquisadores (BRZEZINSKI, 2006; LIBÂNEO, 2005; PIMENTA, 2001; e outros), sempre foi incômoda a sua relação com as outras ciências da educação, tendo em vista a incapacidade delas de dar conta da especificidade do objeto educacional, o que em muitas experiências acontece em função da finalidade social e política a que ela se propõe ou pelos componentes ideológicos aos quais ela se submete. 


\section{Os homens no estágio curricular do Curso de Pedagogia: um olhar para a Educação Infantil e anos iniciais ${ }^{3}$}

A discussão da Educação Infantil neste trabalho se justifica por dois aspectos. Em primeiro lugar, pela relação que os/as discentes fazem do Curso de Licenciatura em Pedagogia com o referido nível de ensino. Nenhuma das atividades para as quais o Curso de Pedagogia forma, seja como fator de rebaixamento ou enaltecimento do curso, seja por preconceito ou desconhecimento, pois chegam a dizer que é somente isso que o pedagogo faz, é tão apontada como área de atuação do pedagogo como o é a Educação Infantil.

Em segundo lugar, porque, embora os/as professores/as e/ou coordenadores/as, os quais possuem conhecimento sobre o currículo, atribuam à docência a principal atividade para a qual o curso forma, todos/as são conscientes de que a Educação Infantil é apenas uma das áreas de atuação do/a pedagogo/a como docente. Isso trouxe a necessidade de compreender mais o papel da Educação Infantil no Curso de Licenciatura em Pedagogia, os fatores pelos quais essa atividade foi colocada pelos discentes como única atribuição do pedagogo e como um campo de trabalho feminino.

Na grande maioria das instituições que oferecem a Educação Infantil, não existem homens, não se aceitam homens estagiários e, entre as poucas experiências com a presença masculina, os homens têm sido figuras solitárias e vistas com desconfiança pela comunidade escolar. Nas entrevistas, há depoimentos revelando as dificuldades de aceitação dos homens nos estágios em Educação Infantil. Entre outros, apresenta-se o relato de Mariano, mas as experiências mostram que há homens que contrariam esses estereótipos, como o exemplo da experiência relatada pela Professora Crisálida:

[...] é um prazer estar trabalhando com crianças, a dificuldade que a gente sente, sendo homem mesmo em sala de aula, é a questão da visão da família isso na educação infantil, primeiro tem aquele pensamento "o que que a família vai dizer quando me ver dando aula para essas crianças. Primeiro porque tem aquele órgão, a Semec... 'não, você não vai para a educação infantil'. O que eles fizeram: como eu era homem, na de ensino fundamental tinha 2 escolas e uma já estava sendo lotada e era mulher e ela... trocaram a mulher do ensino fundamental por educação infantil e me colocaram no ensino fundamental. Eu também

\footnotetext{
${ }^{3}$ A formação de professores para a Educação Infantil e anos iniciais e a infância que considero neste estudo,

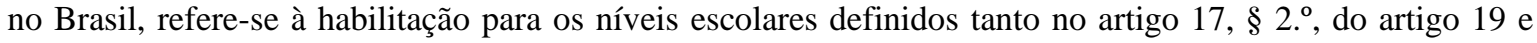
artigo 30 da Lei n. ${ }^{\circ}$ 5.692/1971, no período de sua vigência, quanto no item I do artigo 21 e no artigo 62 da atual Lei n. ${ }^{\circ}$ 9.394/1996 (BRZEZINSKI, 2008). Isto porque nas Leis de Diretrizes e Bases da Educação Nacional brasileira, citadas neste estudo, embora a criança seja contemplada, há diferenças no direito à escola com relação à faixa etária, pois a Lei n. ${ }^{\circ}$ 5.692/1971 não reconhecia a Educação Infantil, nível de educação que foi criado e assegurado somente com a Lei n. ${ }^{\circ}$ 9.394/1996, em vigor no País.
} 
não questionei, disseram: "você vai ficar aqui porque você é do sexo masculino", deixaram claro isso, e disseram: "sexo masculino não dá certo em educação infantil" expressaram isso de cara, ai onde é que vem o erro (MARIANO, VII BLOCO PEDAGOGIA, U-A).

[...]. Eu mesma acompanhei uns alunos de estágio na UFPI, fui professora substituta lá dois anos, na UFPI. 2013, 2014, 2015, saí o ano passado. Saí de lá, vim pra cá. Eu tinha um aluno, o Thompson. O jeito dele assim, o jeito militar. "Esse aluno aí vai dar trabalho no estágio", pensavam, né, pelo jeito grosseiro dele. Quando eu fui visitar ele na escola que eu vi o jeito dele tratar as crianças, a paciência que ele tinha, que ele sentava... os meninos... a confiança dele era tão grande no estágio que ele não faltava. A diretora, a professora elogiava o trabalho dele. "Que, ave maria! Nunca pensou uma pessoa daquela ali, tão empenhada em fazer um bom trabalho". E às vezes assim a pessoa subestima a capacidade do homem em trabalhar com criança... (CRISÁLIDA, PROFESSORA COORDENADORA, F-B).

Não apenas faz parte do discurso, mas também está nas competências necessárias para essa área. Se para o universo do alunado a música tiver um grande impacto pedagógico, então precisamos dominar essa atividade, essa competência, precisamos dominar habilidades, as competências necessárias para aquele alunado com que vamos trabalhar. Há uma ideia socialmente difundida de que os homens ou mulheres de mais idade, pela posição de pai, mãe e, especialmente, avô e avó, teriam mais facilidade de se relacionar ou de cuidar das crianças, essa concepção não cede espaço aos preconceitos de sexo, de gênero e até de idade, é o que mostra o depoimento da Professora Coordenadora Olga:

Então, vejo assim né, o sexo masculino nessa idade de um senhor de 50 anos trabalhar com criança de 0 a 6 anos de idade, eu acho não muito...perfil profissional. Em termos de habilidade para lidar. Ele pode até saber as teorias, ele pode até saber toda essa parte que exige em termos de conteúdo, mas saber lidar com a criança?! A criança ela requer o quê? Que a pessoa brinque, esteja com ela para todas as atividades lúdicas. Não sei se esse profissional poderia ter esse perfil. Pode até ser que esteja equivocada, mas, aparentemente, acho que não teria (OLGA, PROFESSORA COORDENADORA, U-A).

O Rick falou pra mim depois do estágio dele, que uma mãe chegou e falou assim: "Mas quem é o teu professor é aquele ali?". Eu fazia o estágio pela manhã e ele fazia o estágio à tarde e aí no dia da culminância do projeto uma aluna queria abraçar ele e a mãe não deixou, ela ficou: "Olha o professor, o professor!", e a mãe ficou segurando ela. $O$ caso do Wellington que faz o trabalho de acompanhante terapêutico com crianças autistas, Cunha fala em um livro dele que pra uma criança autista um acompanhante homem em termos de comportamentos é melhor que a mulher e assim eu tenho isso até na minha defesa do TCC (MALU, VIII BLOCO PEDAGOGIA, F-B). 
Quando se pensa a prática educativa e, mais especificamente, quando ela é executada, surgem mais que desafios, revelam-se limitações. Analisando todos esses depoimentos, especialmente o de Malu, percebe-se que é necessário haver orientação para as famílias. Na realidade, isso é consequência de valores do modelo de sociedade androgênico e patriarcal que ainda persistem na sociedade contemporânea. Para quaisquer outros níveis ou modalidades de ensino o trabalho docente exige uma formação pautada no conhecimento técnico e específico ou conteúdo das diversas áreas de conhecimento, mas não ultrapassam o âmbito escolar ou acadêmico. Quando se exigem cuidados básicos essenciais, ou seja, práticas que não só educam, mas também cuidam, extrapola a dimensão cognitiva e/ou educativa porque o exercício de cuidar de uma criança exige habilidades que não são incluídas nos currículos dos cursos de formação de professores destinados à Educação Infantil.

\section{Conclusões reflexivas}

Meus principais interlocutores neste trabalho são homens com características diversas ou diferentes tipos de masculinidades, pois, embora movidos por situações e condições de vida diferenciadas, compartilham aspectos comuns em suas histórias de vida. Em primeiro lugar, são pessoas que sempre perseguiram o ideal de ser sujeitos de suas próprias histórias, enfrentando assim quaisquer barreiras em busca dos seus objetivos. Em segundo lugar, todos eles, independentemente do tempo e dos obstáculos, almejaram muito e conquistaram o ingresso em uma faculdade ou universidade, chegando a pleitear, com êxito, uma formação profissional.

O ingresso deles no Curso de Licenciatura em Pedagogia inaugurou os primeiros passos na mudança de vida de suas famílias. A despeito das dificuldades, foram sujeitos de suas histórias, criaram suas próprias oportunidades educacionais e começam a mudar o que parecia algo predestinado para seu ciclo familiar.

Como mostra Burd (2015, p. 27), “a família não é algo natural, universal, biológico, sendo historicamente datado, mas uma instituição criada pelos seres humanos nas relações, que se constitui de formas diferentes em situações e tempos diferentes, para responder a necessidades sociais".

Considerando o perfil discente das mulheres e dos homens entrevistados neste trabalho, observaram-se alguns aspectos relevantes à construção das masculinidades e das 
feminilidades discentes. Os homens nascem, predominantemente, de famílias muito humildes financeiramente; todos tiveram escolaridade na infância, embora com atraso em alguns casos; todos foram de alguma forma motivados a estudar; mesmo aqueles e aquelas criados sem pai e/ou sem mãe não revelaram carências afetivas na infância; muitos foram influenciados para o ingresso no magistério, mas muitos deles o fizeram após tentativas de inserção em outras profissões; alguns estão com dificuldades no curso de formação, mas passaram a se identificar com o campo da Pedagogia.

Nenhum dos homens ou mulheres deseja deixar o magistério, não demonstram entusiasmo por cargos dirigentes, porém não pretendem trabalhar com crianças e/ou com os anos iniciais do Ensino Fundamental, pois estão interessados em outras atividades, tais como: pedagogia hospitalar; pedagogia empresarial; ensino superior e gestão.

\section{REFERÊNCIAS}

ABREU, Jânio Jorge Vieira de. Masculinidades e Educação Infantil na cultura escolar dos Cursos de Licenciatura em Pedagogia de Teresina - PI, Brasil. 2017. 233 f. Tese (Doutorado em Educação) - Universidade Federal do Piauí, Teresina.

BARROSO, João. Os liceus: organização pedagógica e administração (1836-1960).

Lisboa: Junta Nacional de Investigação Científica e Fundação Calouste Gulbenkian, 1995. $2 \mathrm{v}$.

BRZEZINSKI, Iria. Pedagogia, pedagogos e formação de professores. 6 ed. São Paulo: Papirus, 2006.

BURKE, Peter. O que é história cultural? Rio de Janeiro: Zahar, 2004.

BURD, Miriam. Novas configurações familiares: desafios e soluções para a terapia familiar com pacientes crônicos. Rio de Janeiro: Wak Editora, 2015.

CARVALHO, Marília Pinto de. No coração da sala de aula: gênero e trabalho docente nas séries iniciais. São Paulo: Xamã, 1999.

CONNELL, Robert W. Políticas da masculinidade. Educação \& Realidade, São Paulo, p. 183-206, 1995.

DUARTE, Aparecida Rodrigues Silva. Cultura acadêmica e cultura escolar: relações entre matemáticos e professores de matemática. Rev. Diálogo Educ., Curitiba, v. 8, n. 25, p. 647-662, set./dez., 2008.

FERREIRA, Aurélio Buarque de Holanda. Novo dicionário Aurélio da língua portuguesa. 4. ed. Curitiba: Positivo, 2009. 
JÚLIA, Dominique. A cultura escolar como objeto historiográfico. Tradução: Gizele de Souza. Revista Brasileira de História da Educação. São Paulo, n. 1, p. 9-44, 2001.

LIBÂNEO, José Carlos. Pedagogia e pedagogos, para quê? 10 ed. São Paulo: Cortez, 2005.

LOPES, Antonio de Pádua Carvalho. Imagens do masculino e do feminino: coeducação e profissão docente no Piauí 1894 - 1910. In: FARIA FILHO, Luciano Mendes de. Pesquisa em História da Educação: perspectiva de análises, objetivos e fontes. Belo Horizonte: Horta Grande, 1999. p. 95-110.

LOURO, Guacira Lopes. Gênero, sexualidade e educação: uma perspectiva pósestruturalista. Petrópolis: Vozes, 1997.

MONTEIRO, Marko. Masculinidades em revista: 1960-1990. In: PRIORE, Mary del; AMANTINO, Marcia (Org.). História dos homens no Brasil. São Paulo: Editora Unesp, 2013. p. 335-358.

NOLASCO, Sócrates Álvares. O mito da masculinidade. Rio de Janeiro: Rocco, 1993.

OLIVEIRA, Pedro Paulo de. A construção social da masculinidade. Belo Horizonte: Editora UFMG; Rio de Janeiro: IUPERJ, 2004.

PIMENTA, Selma Garrido. Panorama atual da didática no quadro das ciências da educação: educação, pedagogia e didática. In: PIMENTA, Selma Garrido. (Coord.). Pedagogia, ciência da educação? São Paulo: Cortez, 2001. p. 39-70.

PINCINATO, Daiane Antunes Vieira. Homens e masculinidades na cultura do magistério: uma escolha pelo possível, um lugar para brilhar (São Paulo, 1950 - 1989). 2007. Tese (Doutorado em Educação) - Faculdade de Educação da Universidade de São Paulo - FEUSP, São Paulo.

SOARES, Norma Patrycia Lopes. Escola Normal de Teresina (1864 - 2003): reconstruindo uma memória da formação de professores. 2004. Dissertação (Mestrado em Educação) - Universidade Federal do Piauí, Teresina.

WHITE, Leslie. Os símbolos e o comportamento humano. In: CARDOSO, Fernando Henrique; IANNI, Otávio (Org.). Homem e sociedade: leituras de sociologia geral. São Paulo: Nacional, 1968. p. 193-201.

\section{Como referenciar este artigo}

ABREU Jânio Jorge Vieira de. O curso de pedagogia em instituições de ensino superior de Teresina - Piauí, Brasil: incluindo ou excluindo os homens? Revista Ibero-Americana de Estudos em Educação, Araraquara, v. 13. n. esp. 2, p. 1518-1534, set., 2018. ISSN: 19825587. DOI: 10.21723/riaee.v13.nesp2.set2018.11658

Submetido em: 15/03/2018

Aprovado em: 19/06/2018

RIAEE - Revista Ibero-Americana de Estudos em Educação, Araraquara, v. 13. n. esp. 2, p. 1518-1534, set., 2018. ISSN: $1982-5587$. 